\title{
Oncolytic Virus
}

National Cancer Institute

\section{Source}

National Cancer Institute. Oncolytic Virus. NCI Thesaurus. Code C717.

Manipulated or engineered viruses having oncolytic properties to selectively replicate in and kill targeted cancer cells, leaving normal cells unharmed. 